\title{
DNA in serum extracellular vesicles is stable under different storage conditions
}

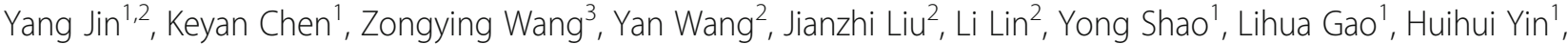 \\ Cong Cui ${ }^{1,2}$, Zhaoli Tan ${ }^{1,2}$, Liejun Liu², Chuanhua Zhao ${ }^{2}$, Gairong Zhang ${ }^{2}$, Ru Jia², Lijuan Du², Yuling Chen², \\ Rongrui Liu ${ }^{2}$, Jianming $\mathrm{Xu}^{2^{*}}$, Xianwen $\mathrm{Hu}^{1 *}$ and Youliang Wang ${ }^{1 *}$
}

\begin{abstract}
Background: Extracellular vesicles (EVs), including exosomes, microvesicles, and apoptotic bodies, can be secreted by most cell types and released in perhaps all biological fluids. EVs contain multiple proteins, specific lipids and several kinds of nucleic acids such as RNAs and DNAs. Studies have found that EVs contain double-stranded DNA and that genetic information has a certain degree of consistency with tumor DNA. Therefore, if genes that exist in exosomes are stable, we may be able to use EVs genetic testing as a new means to monitor gene mutation.

Methods: In this study, EVs were extracted from serum under various storage conditions $\left(4{ }^{\circ} \mathrm{C}\right.$, room temperature and repeated freeze-thaw). We used western blotting to examine the stability of serum EVs. Then, we extracted DNA from EVs and tested the concentration changing under different conditions. We further assessed the stability of EVs DNA s using polymerase chain reaction (PCR) and Sanger sequencing.

Results: EVs is stable under the conditions of $4{ }^{\circ} \mathrm{C}$ (for $24 \mathrm{~h}, 72 \mathrm{~h}, 168 \mathrm{~h}$ ), room temperature (for $6 \mathrm{~h}, 12 \mathrm{~h}, 24 \mathrm{~h}$, $48 \mathrm{~h}$ ) and repeated freeze-thaw (after one time, three times, five times). Also, serum DNA is mainly present in EVs, especially in exosomes, and that the content and function of DNA in EVs is stable whether in a changing environment or not. We showed that EVs DNA stayed stable for 1 week at $4{ }^{\circ} \mathrm{C}, 1$ day at room temperature and after repeated freeze-thaw cycles (less than three times). However, DNA from serum EVs after 2 days at room temperature or after five repeated freeze-thaw cycles could be used for PCR and sequencing.

Conclusions: Serum EVs and EVs DNA can remain stable under different environments, which is the premise that EVs could serve as a novel means for genetic tumor detection and potential biomarkers for cancer diagnostics and prognostics.
\end{abstract}

Keywords: Extracellular vesicles, DNA, Stability, Different conditions

\section{Background}

Extracellular vesicles (EVs) are cell-derived membrane vesicles, including exosomes, microvesicles, and other types of membrane vesicles [1]. The best studied of these vesicles are exosomes. Exosomes are nanometer-sized EVs of endocytic origin that are secreted by most cell types, under physiological and pathological conditions upon fusion of multivesicular bodies (MVBs) with the plasma membrane (PM) [2-5]. Recent studies have

\footnotetext{
*Correspondence: jmxu2003@163.com; huxw1969@163.com;

wang_you_liang@aliyun.com

${ }^{2}$ Affiliated Hospital Cancer Center, Academy of Military Medical Sciences, Beijing, China

'Laboratory of Cell Engineering, Institute of Biotechnology, Beijing, China Full list of author information is available at the end of the article
}

shown that exosomes can be released in many and perhaps all biological fluids, including blood [6], urine [7], cerebrospinal fluid [8] breast milk [9], malignant ascites $[10,11]$, saliva [12], tears [13], nasal secretions [14], semen [15], amniotic fluid [16], bronchoalveolar lavage fluid [17] and culture medium supernatant in cell cultures [3]. Although the term exosome was originally raised in 1981 [18], interest in these EVs has increased dramatically in the last few years, after researchers found that they predominantly contain RNA, proteins, and lipids [19], which can reflect the functionality of the host cell and possess molecular signatures or footprints resembling the cell from which they were secreted [20]. Therefore, the EVs has emerged as an important novel 
mediator in facilitating intercellular communication by regulatory molecules in its cargo and inducing physiologic and genetic changes in targeted cells [21].

Compared with different types of RNA, such as messenger RNA (mRNA), microRNA, and noncoding RNA (ncRNA), which have been shown in the Exocarta database [19], less is known about EVs DNA content, although some types of DNA have been reported, such as single-stranded DNA (ssDNA) [22], mitochondrial DNA (mtDNA) [23] and plasmid DNA (pDNA) [24]. The question remains as to whether the DNA cargo is randomly sorted or if it is systematically packed into EVs. A recent report by Mark et al. found that exosomes contain double-stranded DNA (dsDNA)and that exosome DNA can serve as a novel biomarker for cancer detection [25]. Furthermore, an increasing number of studies have emerged showing that different types of DNA in EVs may be associated with various biological functions [26-28].

It is well-known that exosomes contain dsDNA. Also, exosomal DNA (exoDNA) comprises the entire genome, which spans all chromosomes [29] and carries on the mutational status of malignant parental cells [25]. The question is whether exosomes can be utilized as scapegoats for tumor cells to harbor tumor-specific genetic mutations similar to other sources of circulating tumor DNA (ctDNA) [30]. If these assumptions are established, the feasibility of exosomes as new tumor detection indicators will then became a critical question. As we have described above, EVs are widely distributed in various body fluids systems, which make them more accessible than tumor cells. Moreover, if EVs prove to have considerable stability in vitro, they will become the most promising and available samples for cancer genetic detection. In the present study, we extracted DNA of EVs from the blood of cancer patients under different conditions, and its stability was evaluated.

\section{Methods}

\section{Serum samples}

A collection of serum samples was approved by the local ethics committee of the Affiliated Hospital, Academy of Military Medical Sciences. A written informed consent for the serum sampling was obtained preoperatively from all patients with the disclosure of planned analyzes regarding potential prognostic markers.

\section{Isolation of EVs from serum}

Peripheral blood samples from patients with metastatic colorectal cancer (mCRC) were centrifuged at $3000 \mathrm{~g}$ for $15 \mathrm{~min}$ at ambient temperature (within 2 hours of the blood drawing) to remove cells and cell debris. EVs were isolated from the serum using ExoQuick reagent (System Biosciences, Palo Alto, California, USA) [31] or
PureExo $^{\circ}$ Exosome Isolation Kit (101 Bio, Palo Alto, California, USA). For ExoQuick isolation, $120 \mu$ ExoQuick reagents was added to $500 \mu \mathrm{l}$ serum and precipitated $30 \mathrm{~min}$ at $4{ }^{\circ} \mathrm{C}$. Precipitated samples were centrifuged at $1500 \mathrm{~g}$ for $30 \mathrm{~min}$ at room temperature. $120 \mu \mathrm{l}$ ExoQuick reagent was added to the supernatant and precipitated at $4{ }^{\circ} \mathrm{C}$ for another $30 \mathrm{~min}$. Precipitated samples were centrifuged at $1500 \mathrm{~g}$ for $30 \mathrm{~min}$ at room temperature. The pooled EVs pellets were dissolved in the appropriate buffer for DNA or protein analysis. For PureExo ${ }^{\oplus}$ Exosome Isolation Kit, EVs were extracted from $500 \mu \mathrm{l}$ serum according to the instructions in step.

\section{Transmission electron microscopy}

EVs samples $(10 \mu \mathrm{l})$ resuspended in phosphate buffer saline (PBS) were applied to 300 mesh carbon-coated copper grids for $10 \mathrm{~min}$. Excess samples were blotted with filter paper and then negatively stained with $10 \mu \mathrm{l}$ of a $2 \%$ aqueous uranyl acetate solution for $3 \mathrm{~min}$. Stain was blotted dry from the grids with filter paper, and samples were allowed to dry. Samples were then examined in a HITACHI H-7650 transmission electron microscope (HITACHI, Tokyo, Japan) at an accelerating voltage of $80 \mathrm{kV}$.

\section{Proteins extraction and quantification}

EVs samples from $500 \mu \mathrm{l}$ of serum were lysed in $200 \mu \mathrm{l}$ RIPA buffer [65 mM Tris- $\mathrm{HCl} \mathrm{pH} 7.4,150 \mathrm{mM} \mathrm{NaCl}$, 1 mM EDTA, 1 \% NP-40, $0.25 \%$ sodium deoxycholate, protease inhibitors cocktail (Roche Diagnostics, Mannheim, Germany), and phosphatase inhibitor (Biomed, Beijing, China)] and incubated at $0{ }^{\circ} \mathrm{C}$ for at least $30 \mathrm{~min}$. Incubated specimens were then centrifuged at $12,000 \mathrm{rpm}$ for $30 \mathrm{~min}$ at $4{ }^{\circ} \mathrm{C}$. Protein concentration was analyzed by the Pierce $^{\mathrm{TM}}$ BCA protein assay kit (Thermo Fisher Scientific, Wilmington, Delaware, USA).

\section{Western blotting}

A total of $10 \mu \mathrm{g}$ exosomal proteins were loaded on a regular SDS-PAGE gel. Following electrophoresis, gels were transferred to PVDF (polyvinylidene fluoride) membranes (Millipore, Billerica, USA) for western blotting. Membranes were blocked with $5 \%$ nonfat dry milk dissolved in $1 \times$ PBST (PBS plus $0.2 \% \mathrm{v} / \mathrm{v}$ Tween-20) for $2 \mathrm{~h}$ at room temperature, probed with antigen-specific antibodies overnight at $4{ }^{\circ} \mathrm{C}$ and washed with $1 \times$ PBST solution three times. Afterward, membranes were incubated with secondary antibodies for $1 \mathrm{~h}$ at room temperature and washed with $1 \times$ PBST solution three times. Blots were developed with chemiluminescent reagents from Pierce (Thermo Fisher Scientific). 
Table 1 Primers used in PCR reactions

\begin{tabular}{lll}
\hline Gene & Forward primer & Reverse primer \\
\hline KRAS & 5'-CCTGCTGAAAATGACTGAATATA-3' & 5'-TCTATTGTTGGATCATATTCGTC-3' \\
EGFR & 5'-CTCTCTCTGTCATAGGGACTCTG-3' & 5'-AGCAAAGCAGAAACTCACATC-3' \\
p53 & 5'-CAATGGTTCACTGAAGACCCA-3' & 5'-AAGGGACAGAAGATGACAGGG-3' \\
\hline
\end{tabular}

\section{DNA isolation}

Before the DNA isolation, samples were treated with 2000 U/ml DNase I (New England BioLabs, Frankfurt, Germany) for $2 \mathrm{~h}$ at $37{ }^{\circ} \mathrm{C}$ to remove possible nucleic acid contaminants. After treatment, the enzymes were heated to the condition of inactivation at $75{ }^{\circ} \mathrm{C}$ for $10 \mathrm{~min}$ (this step reaction was only used to verify the distribution of serum DNA). First, total DNA was extracted from EVs by using DNA lysis buffer [0.5 \% SDS, $0.05 \mathrm{M}$ EDTA, $0.01 \mathrm{M}$ Tris- $\mathrm{HCl} \mathrm{pH} 8.0,0.1 \mathrm{M} \mathrm{NaCl}$, $200 \mu \mathrm{g} / \mathrm{ml}$ Protease K (Amresco, Solon, Ohio, USA)]. A total of $400 \mu \mathrm{l}$ DNA lysis buffer was added to each tube of EVs. After mixing, the samples were incubated for $24 \mathrm{~h}$ at $55{ }^{\circ} \mathrm{C}$. The serum that EVs had been extracted out of did not need the process above. Second, deproteinization was performed using a balance of phenol and chloroform. Third, DNA was precipitated using $3 \mathrm{M} \mathrm{CH} \mathrm{CHOONa}_{3}$ glycogen and absolute ethanol for
$24 \mathrm{~h}$ at $-20{ }^{\circ} \mathrm{C}$ and resuspended DNA with TE (0.001 M EDTA, $0.01 \mathrm{M}$ Tris- $\mathrm{HCl} \mathrm{pH} \mathrm{8.0)} \mathrm{at} 37{ }^{\circ} \mathrm{C}$ for at least 16 h. The EVs DNA was quantified on a Nano Drop ND-2000 Spectrophotometer (Thermo Fisher Scientific).

\section{PCR analysis and sequencing}

The polymerase chain reaction (PCR) analysis was performed with preamplified DNA products from EVs and serum disposed of EVs samples from patients with different conditions by using specifically designed primers (Table 1). Each experiment has repeated a minimum of three times. The PCR reaction mixture contained $25 \mu \mathrm{l}$ $2 \times$ Taq Master Mix (Sino Bio Technologies, Shanghai, China), $2 \mu \mathrm{l} 1 \times$ primer, $4 \mu \mathrm{l}$ resuspended DNA and double-distilled water up to $50 \mu \mathrm{l}(100 \mathrm{mM}$ dNTP mix, $10 \mathrm{mM}$ of each primer, $5 \mathrm{U} / \mathrm{ml}$ of Taq 5000 DNA polymerase). PCR was performed in a $\mathrm{C} 1000^{\mathrm{TM}}$ Thermal Cycler (Bio-Rad, Hercules, California, USA) and the
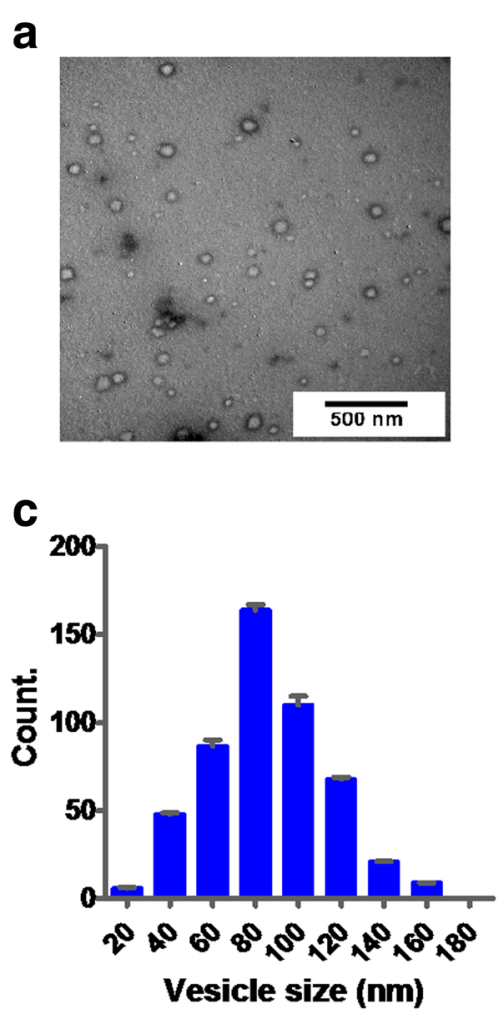

b

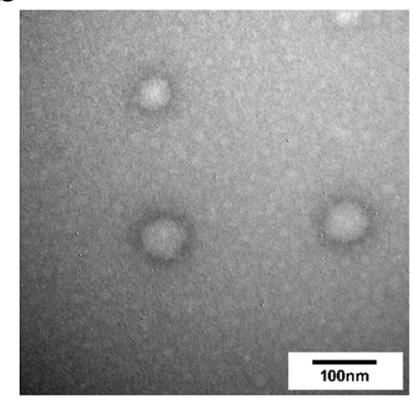

d

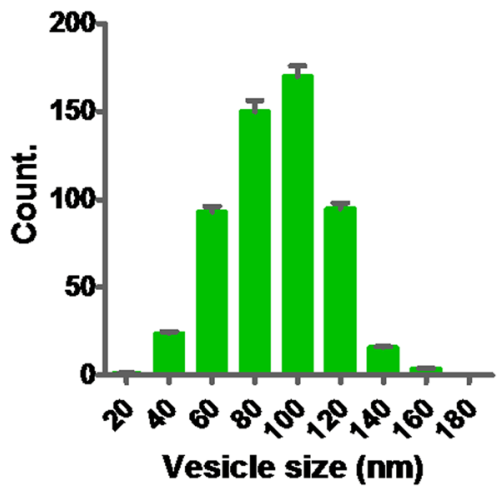

Fig. 1 Morphological characterization and size distribution of EVs. a Micrograph of serum exosomes with low-magnification TEM; b High resolution TEM examination outcomes; $\mathbf{c}$, d Size distribution of the isolated EVs analyzed by TEM and Image-pro Plus. The EVs were counted three times, and the data represented mean \pm SD. EVs were extracted by ExoQuick reagent (c) or by PureExo $0^{\oplus x o s o m e ~ I s o l a t i o n ~ k i t ~(d) ~}$ 
thermal cycles were as follows: 1 cycle of 2 min at $94{ }^{\circ} \mathrm{C}$, 30 cycles for $30 \mathrm{~s}$ at $94{ }^{\circ} \mathrm{C}, 30 \mathrm{~s}$ at $58^{\circ} \mathrm{C}$ and $30 \mathrm{~s}$ at $72{ }^{\circ} \mathrm{C}$, and $5 \mathrm{~min}$ at $72{ }^{\circ} \mathrm{C}$. The resulting PCR products were validated by electrophoresis using $3 \%$ agarose (Amresco) gels. PCR products were sent to Invitrogen Biotechnology to conduct the sequencing analysis.

\section{Results}

\section{Extraction and identification of serum EVs}

We used two different methods to isolate EVs, one of which was the ExoQuick reagent and the other one was Exosome Isolation Kit. Studies have shown that ExoQuick reagent could extract most EVs from blood samples [32, 33] and Exosome Isolation kit could capture most exosomes from serum [34] and that according to the study of 101Bio, using their kit could get $95 \%$ exosome purity. To confirm whether EVs were extracted successfully by the two methods above, harvested serum EVs were analyzed by transmission electron microscopy (TEM) [35]. Particles between 20 and $170 \mathrm{~nm}$ were identified (Fig. 1a, b). The average size of EVs observed in 40 captured images by TEM was $90 \pm 3 \mathrm{~nm}$; most vesicles were between 40 and $140 \mathrm{~nm}$ in diameter, with a peak around $80-100 \mathrm{~nm}$ whether the extraction process using ExoQuick reagent (Fig. 1c) or Exosome Isolation Kit (Fig. 1d). There was no significant difference in the size of the EVs obtained by two methods. So we concluded that the main parts of EVs in serum were exosomes, and we used ExoQuick reagent for EVs extraction taking into account the simplicity of the operation in the follow-up test processes. To ensure that the EVs derived from serum were enriched in exosomes, the isolated vesicles were subjected to exosomal marker analysis. The results of the western blotting (Fig. 2a) showed that only serum $\left(\right.$ serum $^{\mathrm{EV}+}$ ) and EVs contain CD63 and TSG101, which are specific markers of exosomes [36]. However, a serum that had been extracted for EVs (serum ${ }^{\mathrm{EV}-}$ ) did not contain CD63 and TSG101. In addition, albumin, as a ubiquitous protein outside of EVs, mainly existed in serum $^{\mathrm{EV}+}$ and serum ${ }^{\mathrm{EV}}$. Therefore, we extracted the overwhelming majority of serum EVs (especially exosomes) in the blood sample and proved that the EVs extraction process was successful.

\section{Serum DNA dominates in EVs}

Since serum contains different types of DNA, such as cfDNA, ctDNA and exoDNA [26], the extraction process of EVs DNA must reduce external DNA contamination. Two volunteers were randomly selected, and we took two tubes of identical serum samples from each of them to extract EVs. Before the DNA extraction, one copy of EVs and EVs-depleted serum of each patient were treated extensively with DNase I simultaneously, and the other samples remain undisposed.

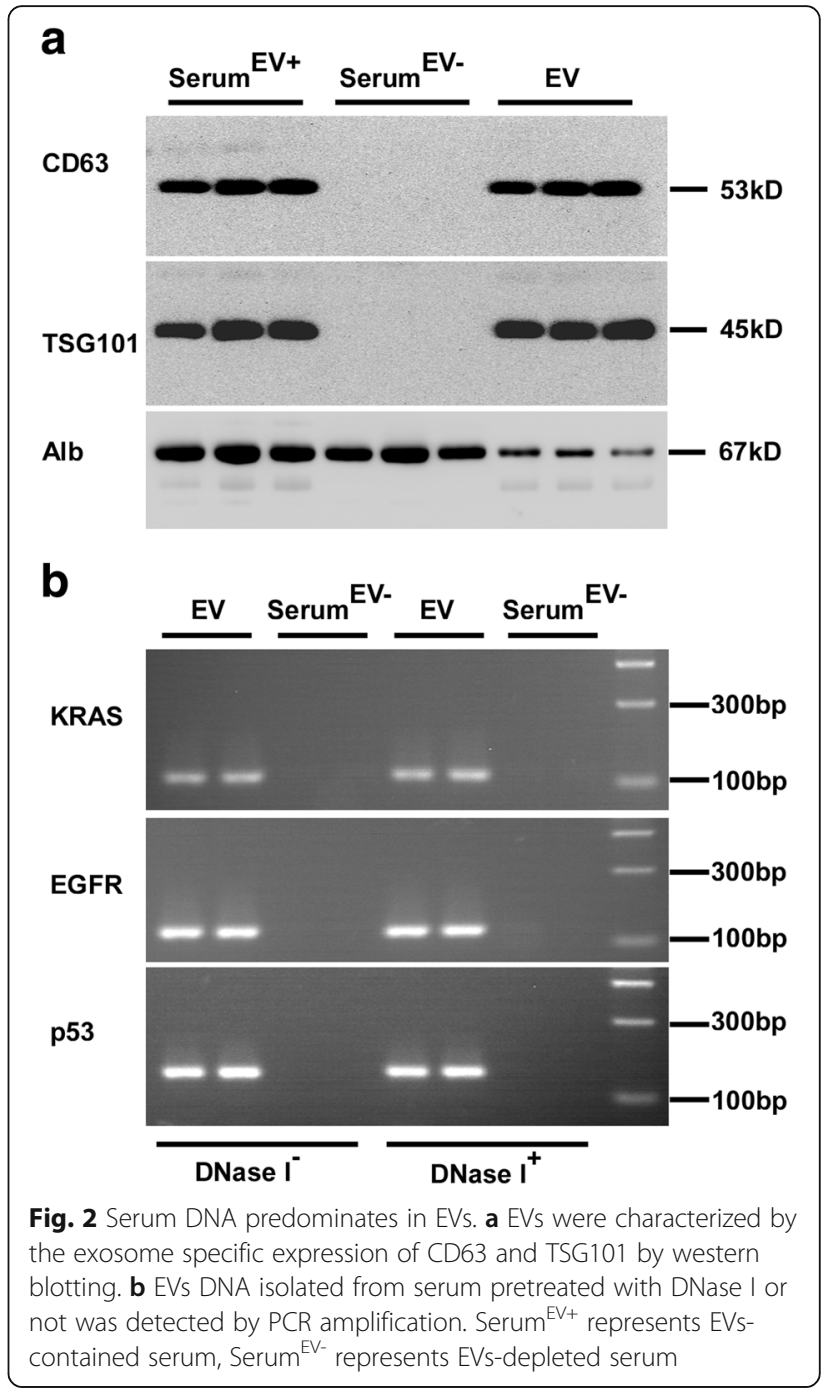

We amplified three fragments of KRAS, EGFR and $p 53$ (Table 1) from EVs DNA to analyze whether DNA is associated with the outer membrane or inside the EVs. We found that with or without DNase I treatment the pattern from each sample was similar (Fig. 2b). And that the DNA gene amplification results were negative in the serum $^{\mathrm{EV}-}$ even the conditions were complete as same as EVs. This result indicated that EV specific DNA predominates in serum DNA.

\section{EVs are stable in different environments}

To assess the impact of disparate storage temperature and different storage time on the stability of EVs, randomly selected freshly isolated serum (after centrifugation of peripheral blood) from three advanced colorectal cancer (CRC) patients was immediately stored at $4{ }^{\circ} \mathrm{C}$ (for $24 \mathrm{~h}, 72 \mathrm{~h}, 168 \mathrm{~h}$ ), room temperature (for $6 \mathrm{~h}, 12 \mathrm{~h}$, $24 \mathrm{~h}, 48 \mathrm{~h}$ ) and $-80{ }^{\circ} \mathrm{C}$ with different freeze-thaw cycles (1 time, 3 times, 5 times). EVs were extracted from the 
stored serum respectively. The serum volume of each patient under different conditions was consistent. An equal volume of proteins, under various conditions, from either EVs (Fig. 3a, b) or EVs-depleted serum (Fig. 3c) was used for western blotting with antibodies specific for CD63. Our results showed that CD63 and TSG101 remained unchanged in EVs exposed to differing environments. Also, as time went on, we detected trace amounts of CD63 on membranes in EVs-depleted serum. We also incubated the membranes, which had previously been exposed to CD63, with an anti-human albumin antibody. As expected, a clear chromogenic albumin emerged in the EVs-depleted serum films (Fig. 3d). Overall, we concluded that the EVs remained stable in serum exposed to differing environments.

\section{EVs DNA is stable under different conditions}

Since serum DNA dominates in EVs (Fig. 2b), we next asked whether EVs DNA was stable under various conditions. Therefore, we verified the concentration of EVs DNA, which was isolated from the EVs mentioned above. As seen in Fig. 4, we detected variations of EVs DNA concentration among the different patient samples. EVs DNA that was extracted from serum which had been stored at $4{ }^{\circ} \mathrm{C}$ was relatively stable (Fig. 4a), in spite of the fact that the concentration of EVs DNA began to decline slowly after $72 \mathrm{~h}$. And apparently, a decrease of concentration from 24 to $48 \mathrm{~h}$ was observed in samples that had been stored at room temperature (Fig. 4b). However, EVs DNA that was subjected to freeze-thaw cycles declined dramatically from 0 to 5 times freeze-thaw
(Fig. 4c). In comparison to the two cases above, exosomes seemed to be more fragile after freeze-thaw.

The observed changes that occurred in PCR (polymerase chain reaction) products were consistent with the EVs DNA concentration (Fig. 5). EVs DNA stayed stable for 1 week at $4{ }^{\circ} \mathrm{C}$ (Fig. 5a), 1 day at room temperature (Fig. 5b) and repeated freeze-thaw three cycles (Fig. 5c), even though there were slight differences among patients and primers. Also, the PCR products of EVsdepleted serum gradually increased, accompanied by vesicle rupture under a variety of extreme conditions. In summary, these results show that EVs DNA is extremely stable, especially at $4{ }^{\circ} \mathrm{C}$.

\section{EVs provides an attractive means for gene detection}

We collected serum samples from two CRC patients. By histological examination, we determined that one CRC patient had a mutated form of the KRAS gene and the other patient was wild-type. The extraction conditions of the EVs were as follows: $0 \mathrm{~h}$ after the blood was centrifuged, $4{ }^{\circ} \mathrm{C}$ for $168 \mathrm{~h}$, room temperature for $48 \mathrm{~h}$ and five freeze-thaw cycles. EVs DNA was isolated from serum that was stored under the above conditions, and the KRAS and p53 PCR products were sequenced (Table 1). Simultaneously, we extracted the leukocytes from these two CRC patients to use for control. Our results showed that PCR amplification from EVs DNA was successful regardless of storage conditions (Fig. 6). The sequencing results showed no significant difference among the different storage conditions compared with the freshly prepared samples (Fig. 6). Moreover, after the 5 -time freeze-thaw cycle, there was a significant decrease
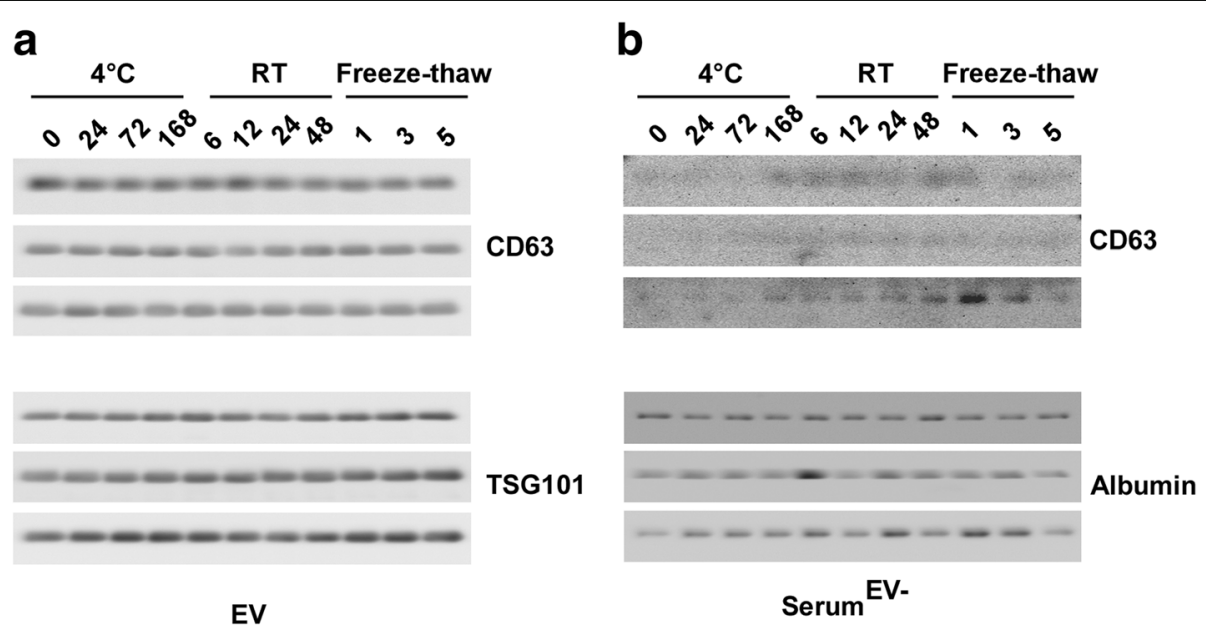

Serum EV-

Fig. 3 Immunoblot of exosome specific markers in EVs and EVs-depleted serum under different conditions. a Immunoblot of CD63 in EVs from the serum of three CRC patients under different conditions. $\mathbf{b}$ Immunoblot of TSG101 in EVs from the serum of three CRC patients under different conditions. c Immunoblot of CD63 in EVs-depleted serum from three CRC patients under different conditions. d Immunoblot of albumin in EVs-depleted serum from three CRC patients under different conditions. Freshly isolated serum randomly selected from three advanced CRC patients was stored at $0 \mathrm{~h}, 4{ }^{\circ} \mathrm{C}(24 \mathrm{~h}, 72 \mathrm{~h}, 168 \mathrm{~h})$, room temperature $(6 \mathrm{~h}, 12 \mathrm{~h}, 24 \mathrm{~h}, 48 \mathrm{~h})$ and $-80^{\circ} \mathrm{C}$ with freeze-thaw (one time, three times, five times) 

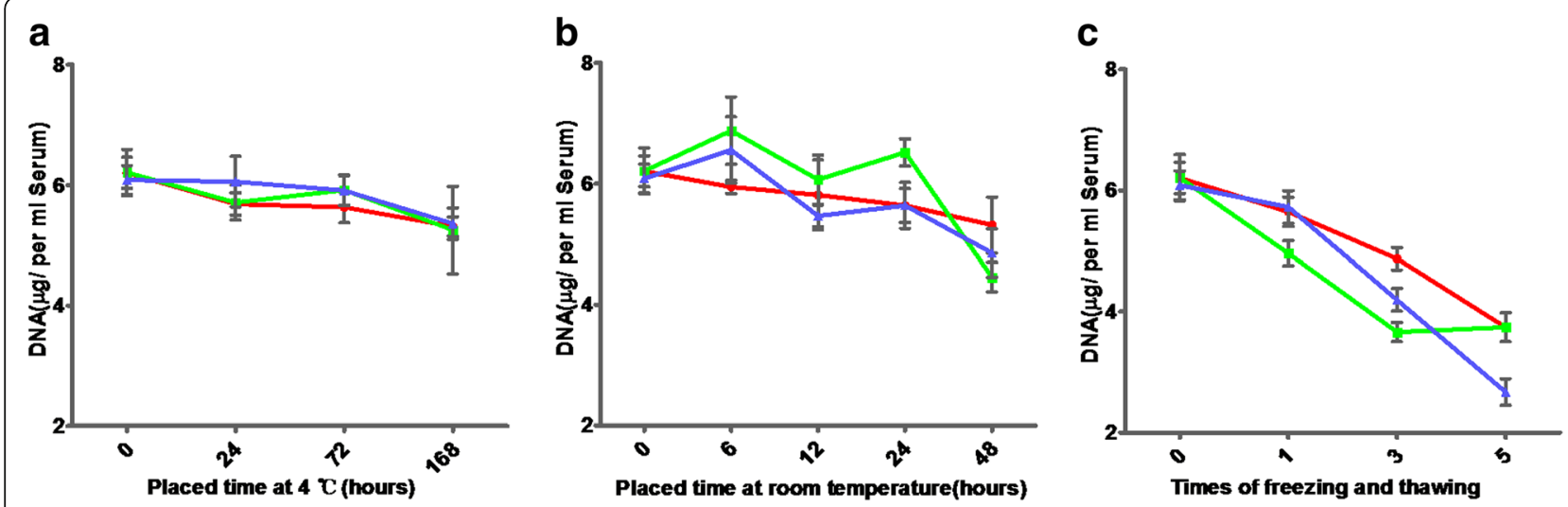

Fig. 4 The concentration of EVs DNA extracted from serum under different conditions. a The concentration of EVs DNA from the serum of three patients stored at $4{ }^{\circ} \mathrm{C}$ for $0,24,72$ and $168 \mathrm{~h}$. $\mathbf{b}$ The concentration of EVs DNA from the serum of three patients stored at room temperature for 0, 6, 12, 24 and $48 \mathrm{~h}$. c The concentration of EVs DNA from the serum of three patients after repeated freeze-thaw 0, 1, 3 and five times

in the sequencing peak values in the samples containing the mutant KRAS gene locus and the wild-type KRAS locus (Fig. 6). Therefore, we conclude that the repeated freeze-thaw condition has the largest impact on the stability of EVs. However, no matter what condition was analyzed, the KRAS mutation was detected in the EVs
DNA, although the sequencing peak value was different (Fig. 6). Furthermore, the genetic testing results between exosomes and tumor cells showed a high degree of consistency. Patient tumor DNA that showed a mutation in exon 2 of the KRAS gene by histological examination showed the same mutation by sequencing in the patient's

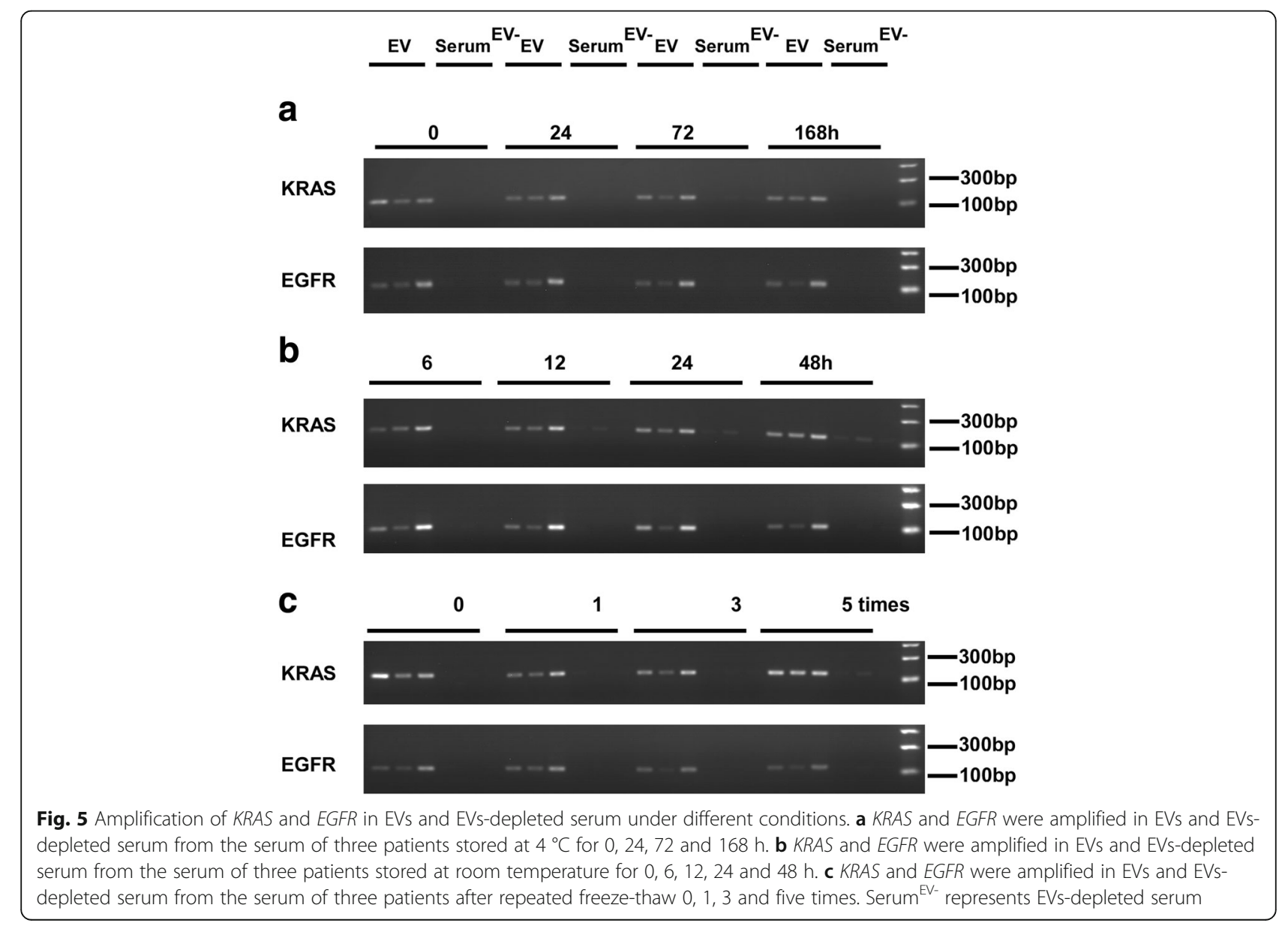




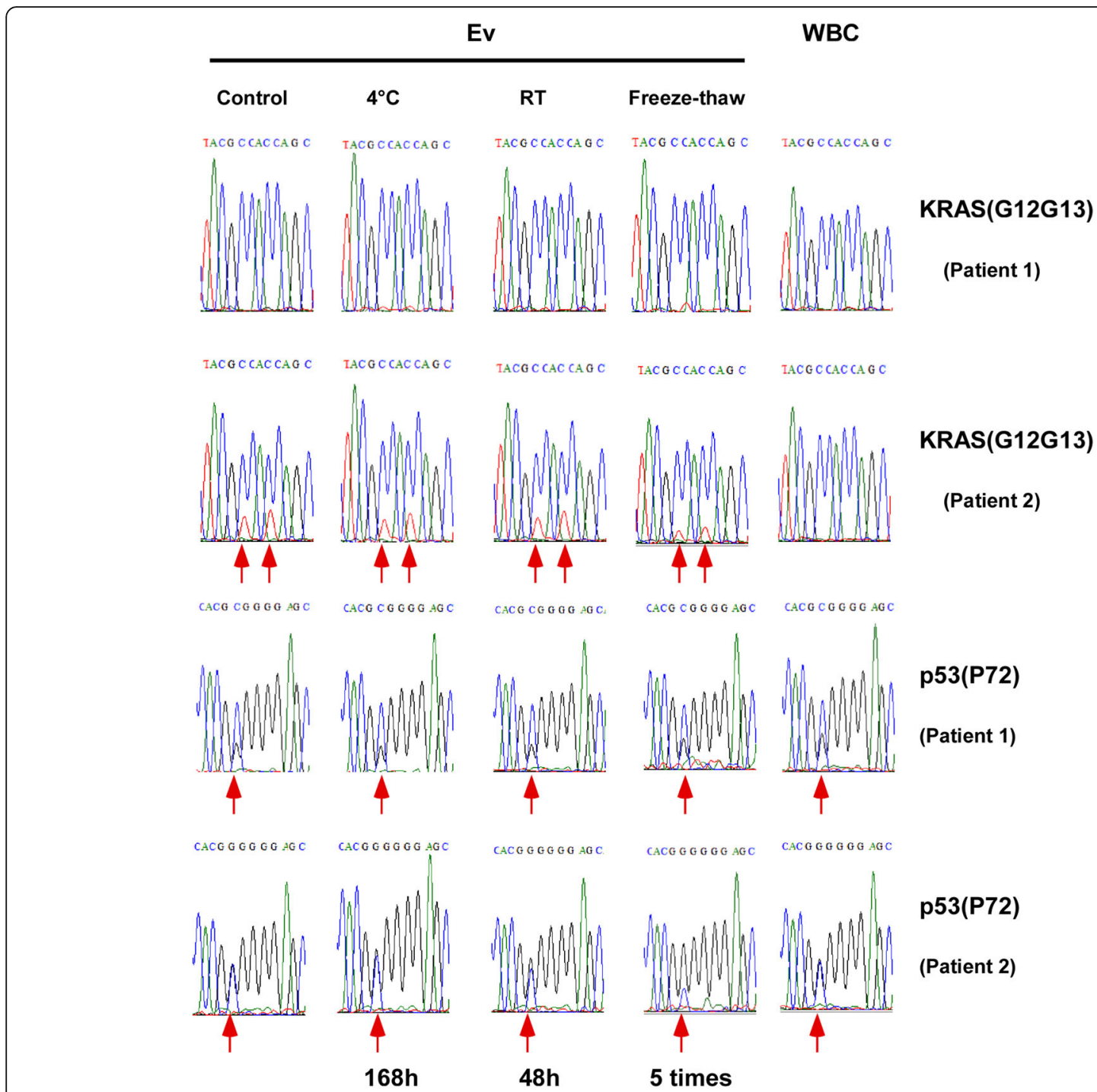

Fig. 6 Sanger sequencing of EVs DNA extracted from serum under different conditions. Sanger sequencing revealed a p53 mutation on codon 72 in EVs DNA from patient 1, a p53 mutation on codon 72 and two KRAS mutations on codon 12 and 13 in EVs DNA from patient 2; white blood cell (WBC) DNA from the same patient was used as a control

EVs DNA. Moreover, no mutations were detected in the somatic cells of patients. In summary, our results suggest that exosomes can be used as an ideal material for gene detection.

\section{Discussion}

Cancer is one of the leading causes of morbidity and mortality in the world, and the treatment of it has evolved during the past two decades. Early diagnosing and effective treatment can significantly reduce cancer mortality, which relies on accurate diagnosis, precise tumor staging, and gene mutation status [37]. As molecular targeted therapy develops, standardized treatment of tumors should depend on the results of gene detection [38]. Genetic testing of tumor tissues is the current gold standard for cancer diagnosis and therapy. Primary lesions and metastatic foci in early tumors are hard to find. Furthermore, as cancer advances, surgery and biopsy is rather difficult, and they are both invasive techniques, which could bring more suffering to the patient. Importantly, results of genetic tests to help guide treatment are not necessarily accurate because tumor tissue is heterogeneous [39]. Therefore, with our current in-depth study of EVs (especially exosomes), we ushered in the dawn to solve this problem.

Exosomes from different cell types have different functions, due to the composition of their functional molecules, which varies from their cell of origin [40-42]. Exosomes contain multiple proteins, DNA, mRNA, microRNA, long noncoding RNA and genetic material 
from viruses/prions [43]. These substances are biochemically and functionally distinct when transferred to a recipient cell where they regulate protein expression and signaling pathways [44]. Tumor-derived exosomes play a significant role in facilitating metastases by strengthening angiogenesis [45]. Evs are emerging as key players in intercellular communication between cancer cells and their microenvironment through horizontal transfer of information via their cargo [25, 46]. Meanwhile, the more noteworthy fact is, serum exosomes from cancer patients contain genomic DNA that spans all chromosomes [29], and that exosomes from cancer patients have a higher concentration than normal cells $[47,48]$. It is well-known that the stability of exosomes depends largely on their bilayer lipid membrane structure to protect biological cargo against degradation and denaturation in the extracellular environment [49]. The focus of our work is for the stability of EVs DNA and possibility of being a novel approach for genetic testing.

In the present study, we tested the stability of serum EVs by analyzing their molecular markers, DNA concentration, PCR amplification, and sequencing from exoDNA. The membrane bilayer structure is the basis for the stability of the exosome; therefore, the exoDNA can be protected from degradation. Similar to mRNA [50], the exoDNA content remains substantially at a constant level after experiencing different treatment conditions. EVs experience a slight rupture with the length of time and increasing the number or freezethaw cycles. We observed an apparent change in DNA concentration from 24 to $48 \mathrm{~h}$ at room temperature. However, the change was not significant on the initial concentration. Nevertheless, the largest degradation of EVs appeared during the freeze-thaw cycles, and subsequent sequencing results also reflect this. Similarly, by DNA electrophoresis we showed that with the deterioration of conditions, such as $4{ }^{\circ} \mathrm{C}$ for $168 \mathrm{~h}$, room temperature for $48 \mathrm{~h}$ and repeated freezing and thawing five times, the serum without intact EVs began to show increasing amounts of DNA products, which implies the rupture of EVs. Also, primer differences exist between different patients under various conditions. Importantly, exosomes are recognized as promising diagnostic and predictive biomarkers in cancer. Therefore, clinicians might use them to guide individual treatments [51]. Our research confirmed that EVs or exosomes exhibit extremely stable characteristics and can protect themselves from material damage by the external environment. EVs show a considerable degree of consistency with tumor cells on the detection of genetic mutation. Therefore EVs may be a suitable choice for genetic testing and/or guiding the individual treatment of a patient.

\section{Conclusions}

In conclusion, Serum EVs, and EVs DNA can remain stable under different storage environments, which is the premise that EVs could be serve as a novel means for tumor genetic detection and potential biomarkers for cancer diagnostics and prognostics. Furthermore, maybe we can monitor changes in EVs gene during patients treatment to better guide individualized therapy.

\begin{abstract}
Abbreviations
cfDNA: cell free DNA; CRC: colorectal cancer; ctDNA: circulating tumor DNA: dsDNA: double-stranded DNA; EVs: Extracellular vesicles; exoDNA: exosomal DNA; mCRC: metastatic colorectal cancer; mRNA: messenger RNA; mtDNA: mitochondrial DNA; MVB: Multivesicular bodies; ncRNA: noncoding RNA; PBS: Phosphate buffer saline; PCR: Polymerase chain reaction; pdna: plasmid DNA; PM: Plasma membrane; PVDF: Polyvinylidene fluoride; SsDNA: single-stranded DNA
\end{abstract}

\section{Acknowledgements}

We thank Fangfei Li from Sanford-Burnham-Prebys Medical Discovery Institute at Lake Nona, for statistical review.

\section{Funding}

This work was supported by National Natural Science Foundation of China (No. 81172280, 81573458) and China Major National Science and Technology Project Grant(2016ZX08006002-004).

\section{Availability of data and materials}

The datasets supporting the conclusions of this article are included in the article.

\section{Authors' contributions}

YLW, XWH, and JMX conceived and designed the study. YJ, KYC, YS, HHY and ZYW carried out the molecular biology studies. YJ and KYC drafted the manuscript and the figures. JZL, LL, CHZ, GRZ, RJ, LD, YLC, RRL, LL, YW, ZLT, and CC collected the serum samples. YJ, KYC, and LHG performed the statistical analysis. YLW modified the manuscript. All authors read and approved the final version of the manuscript and agree to be accountable for all aspects of the work.

\section{Competing interests}

The authors declare that they have no competing interest.

\section{Consent for publication}

Not applicable.

\section{Ethics approval and consent to participate}

The study was approved by the local ethics committee of the Affiliated Hospital, Academy of Military Medical Sciences (2014-135). The procedures of the study followed were by the ethical standards of the committee on human experimentation of the hospital. A written informed consent for the serum sampling was obtained preoperatively from all patients with the disclosure of planned analyzes regarding potential prognostic markers. The participants declared that their sample and data are only used for this research in the signed informed consent, and the data could not be used in other research.

\section{Author details}

${ }^{1}$ Laboratory of Cell Engineering, Institute of Biotechnology, Beijing, China. ${ }^{2}$ Affiliated Hospital Cancer Center, Academy of Military Medical Sciences, Beijing, China. ${ }^{3}$ Department of Ultrasonics, People's Hospital, Donggang District, Rizhao, Shandong Province, China.

Received: 20 April 2016 Accepted: 15 September 2016 Published online: 23 September 2016

\section{References}

1. Raposo G, Stoorvogel W. Extracellular vesicles: exosomes, microvesicles, and friends. J Cell Biol. 2013;200:373-83.

2. Hendrix A, Westbroek W, Bracke M, De Wever O. An ex (o) citing machinery for invasive tumor growth. Cancer Res. 2010;70:9533-7. 
3. Kanada M, Bachmann MH, Hardy JW, Frimannson DO, Bronsart L, Wang A, et al. Differential fates of biomolecules delivered to target cells via extracellular vesicles. Proc Natl Acad Sci. 2015;112:E1433-42.

4. Keller S, Sanderson MP, Stoeck A, Altevogt P. Exosomes: from biogenesis and secretion to biological function. Immunol Lett. 2006;107:102-8.

5. Simpson RJ, Lim JW, Moritz RL, Mathivanan S. Exosomes: proteomic insights and diagnostic potential. Expert Rev Proteomics. 2009;6:267-83.

6. Caby MP, Lankar D, Vincendeau-Scherrer C, Raposo G, Bonnerot C. Exosomal-like vesicles are present in human blood plasma. Int Immunol. 2005;17:879-87.

7. Kumari N, Saxena S, Agrawal U. Exosomal protein interactors as emerging therapeutic targets in urothelial bladder cancer. J Egypt Natl Canc Inst. 2015:27:51-8.

8. Tominaga N, Kosaka N, Ono M, Katsuda T, Yoshioka Y, Tamura K, et al. Brain metastatic cancer cells release microRNA-181c-containing extracellular vesicles capable of destructing blood-brain barrier. Nat Commun. 2015;6:6716.

9. Zonneveld MI, Brisson AR, van Herwijnen MJ, Tan S, van de Lest CH, Redegeld FA, et al. Recovery of extracellular vesicles from human breast milk is influenced by sample collection and vesicle isolation procedures. J Extracell Vesicles. 2014;3:24215.

10. Andre F, Schartz NE, Movassagh M, Flament C, Pautier P, Morice $P$, et al. Malignant effusions and immunogenic tumour-derived exosomes. Lancet. 2002;360:295-305.

11. Bard MP, Hegmans JP, Hemmes A, Luider TM, Willemsen R, Severijnen LAA, et al. Proteomic analysis of exosomes isolated from human malignant pleural effusions. Am J Respir Cell Mol Biol. 2004;31:114-21.

12. Schageman J, Zeringer E, Li M, Barta T, Lea K, Gu J, et al. The complete exosome workflow solution: from isolation to characterization of RNA cargo. Biomed Res Int. 2013;2013:253957.

13. Yang C, Robbins PD. The roles of tumor-derived exosomes in cancer pathogenesis. Clin Dev Immunol. 2011;2011:842849.

14. Qazi KR, Paredes PT, Dahlberg B, Grunewald J, Eklund A, Gabrielsson S. Proinflammatory exosomes in bronchoalveolar lavage fluid of patients with sarcoidosis. Thorax. 2010;65:1016-24.

15. Vojtech L, Woo S, Hughes S, Levy C, Ballweber L, Sauteraud RP, et al. Exosomes in human semen carry a distinctive repertoire of small noncoding RNAs with potential regulatory functions. Nucleic Acids Res. 2014;42: 7290-304.

16. Keller S, Ridinger J, Rupp A-K, Janssen JW, Altevogt P. Body fluid derived exosomes as a novel template for clinical diagnostics. J Transl Med. 2011;9:240.

17. Admyre C, Grunewald J, Thyberg J, Gripenbäck S, Tornling G, Eklund A, et al. Exosomes with major histocompatibility complex class II and co-stimulatory molecules are present in human BAL fluid. Eur Respir J. 2003;22:578-83.

18. Trams EG, Lauter CJ, Salem JN, Heine U. Exfoliation of membrane ecto-enzymes in the form of micro-vesicles. Biochim Biophys Acta. 1981;645:63-70.

19. Mathivanan S, Fahner CJ, Reid GE, Simpson RJ. ExoCarta 2012: database of exosomal proteins, RNA and lipids. Nucleic Acids Res. 2012;40:D1241-4.

20. Mathivanan S, Lim JW, Tauro BJ, Ji H, Moritz RL, Simpson RJ. Proteomics analysis of A33 immunoaffinity-purified exosomes released from the human colon tumor cell line LIM1215 reveals a tissue-specific protein signature. Mol Cell Proteomics. 2010;9:197-208.

21. Théry C. Exosomes: secreted vesicles and intercellular communications. F1000 Bio Rep. 2011;3:11

22. Balaj L, Lessard R, Dai L, Cho Y-J, Pomeroy SL, Breakefield XO, et al. Tumour microvesicles contain retrotransposon elements and amplified oncogene sequences. Nat Commun. 2011;2:180.

23. Guescini M, Genedani S, Stocchi V, Agnati LF. Astrocytes and Glioblastoma cells release exosomes carrying mtDNA. J Neural Transm. 2010;117:1-4.

24. Shader RI. Cell-to-cell talk: plasmids and exosomes. Clin Ther. 2014;6:817-8.

25. Thakur BK, Zhang H, Becker A, Matei I, Huang Y, Costa-Silva B, et al. Doublestranded DNA in exosomes: a novel biomarker in cancer detection. Cell Res. 2014;24:766-9.

26. Gold B, Cankovic M, Furtado LV, Meier F, Gocke CD. Do Circulating Tumor Cells, Exosomes, and Circulating Tumor Nucleic Acids Have Clinical Utility? A Report of the Association for Molecular Pathology. J Mol Diagn. 2015;17: 209-24

27. Lázaro-Ibáñez E, Sanz-Garcia A, Visakorpi T, Escobedo-Lucea C, Siljander P, Ayuso-Sacido Á, et al. Different gDNA content in the subpopulations of prostate cancer extracellular vesicles: apoptotic bodies, microvesicles, and exosomes. Prostate. 2014;74:1379-90.
28. Srivastava A, Filant J, Moxley KM, Sood A, McMeekin S, Ramesh R. Exosomes: a role for naturally occurring nanovesicles in cancer growth, diagnosis and treatment. Curr Gene Ther. 2015;15:182-92.

29. Kahlert C, Melo SA, Protopopov A, Tang J, Seth S, Koch M, et al. Identification of double-stranded genomic DNA spanning all chromosomes with mutated KRAS and p53 DNA in the serum exosomes of patients with pancreatic cancer. J Bio Chem. 2014;289:3869-75.

30. Schwarzenbach H, Hoon DS, Pantel K. Cell-free nucleic acids as biomarkers in cancer patients. Nat Rev Cancer. 2011;11:426-37.

31. Okoye IS, Coomes SM, Pelly VS, Czieso S, Papayannopoulos V, Tolmachova T, et al. MicroRNA-containing T-regulatory-cell-derived exosomes suppress pathogenic T helper 1 cells. Immunity. 2014;41:89-103.

32. Njock M-S, Cheng HS, Dang LT, Nazari-Jahantigh M, Lau AC, Boudreau E, et al. Endothelial cells suppress monocyte activation through secretion of extracellular vesicles containing antiinflammatory microRNAs. Blood. 2015;125:3202-12.

33. Saá P, Yakovleva O, de Castro J, Vasilyeva I, De Paoli SH, Simak J, et al. First demonstration of transmissible spongiform encephalopathy-associated prion protein (PrPTSE) in extracellular vesicles from plasma of mice infected with mouse-adapted variant Creutzfeldt-Jakob disease by in vitro amplification. J Bio Chem. 2014;289:29247-60.

34. Chen L, Chen R, Kemper S, Charrier A, Brigstock DR. Suppression of fibrogenic signaling in hepatic stellate cells by Twist1-dependent microRNA214 expression: Role of exosomes in horizontal transfer of Twist1. Am J Physiol Gastrointest Liver Physiol. 2015;309:G491-9.

35. Costa-Silva B, Aiello NM, Ocean AJ, Singh S, Zhang H, Thakur Basant K, et al. Pancreatic cancer exosomes initiate pre-metastatic niche formation in the liver. Nat Cell Biol. 2015;17:816-26.

36. Théry C, Ostrowski M, Segura E. Membrane vesicles as conveyors of immune responses. Nat Rev Immunol. 2009;9:581-93.

37. National Comprehensive Cancer Network. Clinical Practice Guidelines in Oncology. Colon cancer Version 2. 2015.

38. Dietel M, Jöhrens K, Laffert M, Hummel M, Bläker H, Pfitzner B, et al. A 2015 update on predictive molecular pathology and its role in targeted cancer therapy: a review focussing on clinical relevance. Cancer Gene Ther. 2015;22:41730.

39. Alizadeh AA, Aranda V, Bardelli A, Blanpain C, Bock C, Borowski C, et al. Toward understanding and exploiting tumor heterogeneity. Nat Med. 2015; 21:846-53.

40. Hajrasouliha AR, Jiang G, Lu Q, Lu H, Kaplan HJ, Zhang H-G, et al. Exosomes from retinal astrocytes contain antiangiogenic components that inhibit laser-induced choroidal neovascularization. J Bio Chem. 2013;288:28058-67.

41. Yang M, Chen J, Su F, Yu B, Su F, Lin L, et al. Microvesicles secreted by macrophages shuttle invasion-potentiating microRNAs into breast cancer cells. Mol Cancer. 2011:10:541-52.

42. Zhang H-G, Grizzle WE. Exosomes and cancer: a newly described pathway of immune suppression. Clin Cancer Res. 2011;17:959-64.

43. Meckes Jr DG, Shair KH, Marquitz AR, Kung CP, Edwards RH, Raab-Traub N. Human tumor virus utilizes exosomes for intercellular communication. Proc Natl Acad Sci U S A. 2010;107:20370-5.

44. Xu R, Greening DW, Rai A, Ji H, Simpson RJ. Highly-purified exosomes and shed microvesicles isolated from the human colon cancer cell line LIM1863 by sequential centrifugal ultrafiltration are biochemically and functionally distinct. Methods. 2015.

45. Park JE, Tan HS, Datta A, Lai RC, Zhang H, Meng W, et al. Hypoxic tumor cell modulates its microenvironment to enhance angiogenic and metastatic potential by secretion of proteins and exosomes. Mol Cell Proteomics. 2010; 9:1085-99.

46. Mittelbrunn M, Sánchez-Madrid F. Intercellular communication: diverse structures for exchange of genetic information. Nat Rev Mol Cell Biol. 2012:13:328-35.

47. Rabinowits G, Gerçel-Taylor C, Day JM, Taylor DD, Kloecker GH. Exosomal microRNA: a diagnostic marker for lung cancer. Clin Lung Cancer. 2009:10:42-6.

48. Silva J, Garcia V, Rodriguez M, Compte M, Cisneros E, Veguillas $P$, et al. Analysis of exosome release and its prognostic value in human colorectal cancer. Genes Chromosomes Cancer. 2012:51:409-18.

49. Taylor DD, Gercel-Taylor C. MicroRNA signatures of tumor-derived exosomes as diagnostic biomarkers of ovarian cancer. Gynecol Oncol. 2008;110:13-21.

50. Ge Q, Zhou Y, Lu J, Bai Y, Xie X, Lu Z. miRNA in plasma exosome is stable under different storage conditions. Molecules. 2014;19:1568-75.

51. Bertotti A, Papp E, Jones S, Adleff V, Anagnostou V, Lupo B, et al. The genomic landscape of response to EGFR blockade in colorectal cancer. Nature. 2015;526(7572):263-7. doi:10.1038/nature14969. 